\title{
FLORA DE GRÃO-MOGOL, MINAS GERAIS: PIPERACEAE ${ }^{1}$
}

\author{
EDUARDO G. GONÇALVES* \\ Departamento de Botânica, Instituto de Biociências, Universidade de São Paulo, \\ Caixa Postal 11461, 05422-970 - São Paulo, SP, Brasil. \\ *endereço atual: Universidade Católica de Brasília, Curso de Ciências Biológicas, Sala M-026, QS 7, lote 1, EPTC - Águas Claras, \\ 71966-700 - Taguatinga, DF, Brasil.
}

Trelease, W. \& Yunker, T.G. 1950. The Piperaceae of Northern South America. University of Illinois Press. Urbana. Yunker, T.G. 1974. The Piperaceae of Brazil III: Peperomia; taxa of uncertain status. Hoehnea 4:73-413.

1. Peperomia Ruiz \& Pav.

Ervas perenes, ocasionalmente anuais, terrestres, epífitas ou rupícolas, normalmente suculentas; folhas alternas, opostas ou verticiladas, venação usualmente pouco proeminente; espiga axilar, terminal ou oposta em relação à folha, densiflora a laxiflora; flores bissexuadas, aperiantadas, guarnecidas por uma bráctea normalmente glabra; estames 2, laterais; ovário monocarpelar, uniovulado, estigma geralmente séssil; fruto drupáceo, séssil ou pedicelado; semente com endosperma escasso.

1. Folhas alternas, $25-50 \mathrm{~mm}$ compr. P. subrubricaulis

1 '. Folhas verticiladas (3-4), nunca mais longas que $15 \mathrm{~mm}$ compr.

2. Plantas glabras; lâmina com pontuações glandulares na face abaxial P. quadrifolia

$2^{\prime}$. Ramos e folhas puberulentas; lâmina sem pontuações glandulares P. tetraphylla

1.1. Peperomia quadrifolia (L.) Humb., Bonpl. \& Kunth, Nov. gen. sp. 1: 69. 1815.

Erva rupícola, ramos eretos, glabros, $15-30 \mathrm{~cm}$ alt. Folhas 3-4 verticiladas, elípticas a obovadas, 7-11 mm compr., 4-7 mm larg., subcoriáceas, glabras, moderadamente coberta de pontuações glandulares adaxialmente, ápice arredondado, base aguda a cuneada, nervuras levemente proeminentes abaxialmente, praticamente invisiveis adaxialmente, pecíolo ca. $1 \mathrm{~mm}$ compr. Espigas terminais, densifloras, $2,5 \mathrm{~cm}$ compr., 1-1,5 mm diâm.; pedúnculo glabro, 2,5 cm compr.; Flores com brácteas arredondadas; drupas $1 \mathrm{~mm}$ compr., elipsoidais, estigma apical, levemente obliquo (Fig 1. C-F).

Cavalcanti et al. CFCR 8479 (SPF).

Distribui-se por toda a região neotropical, incluindo Américas do Sul e Central e Índias Ocidentais. Pode ser reconhecida pelas folhas usualmente obovadas, de ápice arredondado, sempre glabras e cobertas de pontuações glandulares. Em Grão-Mogol cresce sobre pedras, e foi coletada com flores no mês de novembro.
1.2. Peperomia subrubricaulis C.DC., Bull. Herb. Boiss. 2(7): 141. 1907.

Erva rupícola, ramos eretos a decumbentes na base, pubescentes, avermelhados, $10-19 \mathrm{~cm}$ alt. Folhas alternas, ovadas a elípticas 2,7-50 cm compr., 1,5-2,4 cm larg., subcoriáceas, pubescentes abaxialmente, glabrescentes adaxialmente, nervuras moderadamente visíveis em ambas as faces, ápice obtuso a cuspidado, base cuneada, pecíolo 5-7 mm compr.. Espigas axilares ou terminais, 9,5-12 cm compr., 1-2 mm diâm., laxifloras; pedúnculos ca. $1 \mathrm{~cm}$ compr., 1 mm diâm.. Flores com brácteas arredondadas; drupas ovóides, estigma subapical de ápice oblíquo (Fig. 1 A-B).

Zappi et al. CFCR $8480(\mathrm{SPF})$

Espécie apenas conhecida do estado de Minas Gerais. Pode ser reconhecida pelas folhas ovadas ou elípticas, sempre alternas. Em Grão-Mogol esta espécie é rupícola, apresentando flores no mês de setembro.

1.3. Peperomia tetraphylla (G. Forst.) Hook. \& Arn., Bot. Beechey Voy. 97. 1841.

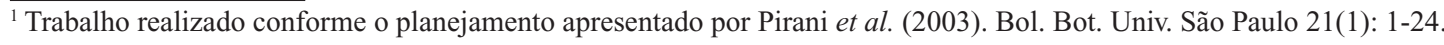


Erva rupícola, ramos eretos, pubescentes, $14-22 \mathrm{~cm}$ alt. Folhas 2-4 verticiladas, largo obovadas a orbiculares, 4-8 mm compr., 4-7 mm larg., subcoriáceas, pubescentes, ápice arredondado, base obtusa a arredondada, nervuras não visíveis em ambas as superfícies. Espigas terminais, 1,7-2,1 cm compr.; 1-1,5 mm diâm., densifloras; pedúnculo pubescente, 1,2-1,8 cm compr., 0,5-0,6 mm diâm.. Flores com brácteas arredondadas; drupas ca. $1 \mathrm{~mm}$ compr., cilíndrico, estigma apical (Fig. $1 \mathrm{G}-\mathrm{H}$ ).

\section{Rossi et al. CFCR 1024 (SPF)}

Esta espécie tem distribuição pantropical, coincidindo com a distribuição do próprio gênero. Pode ser reconhecida pelas folhas largo obovadas, pubescentes, surgindo em número de quatro em cada nó. Em Grão-Mogol esta espécie é terrestre, crescendo às margens da estrada, florescendo em abril.

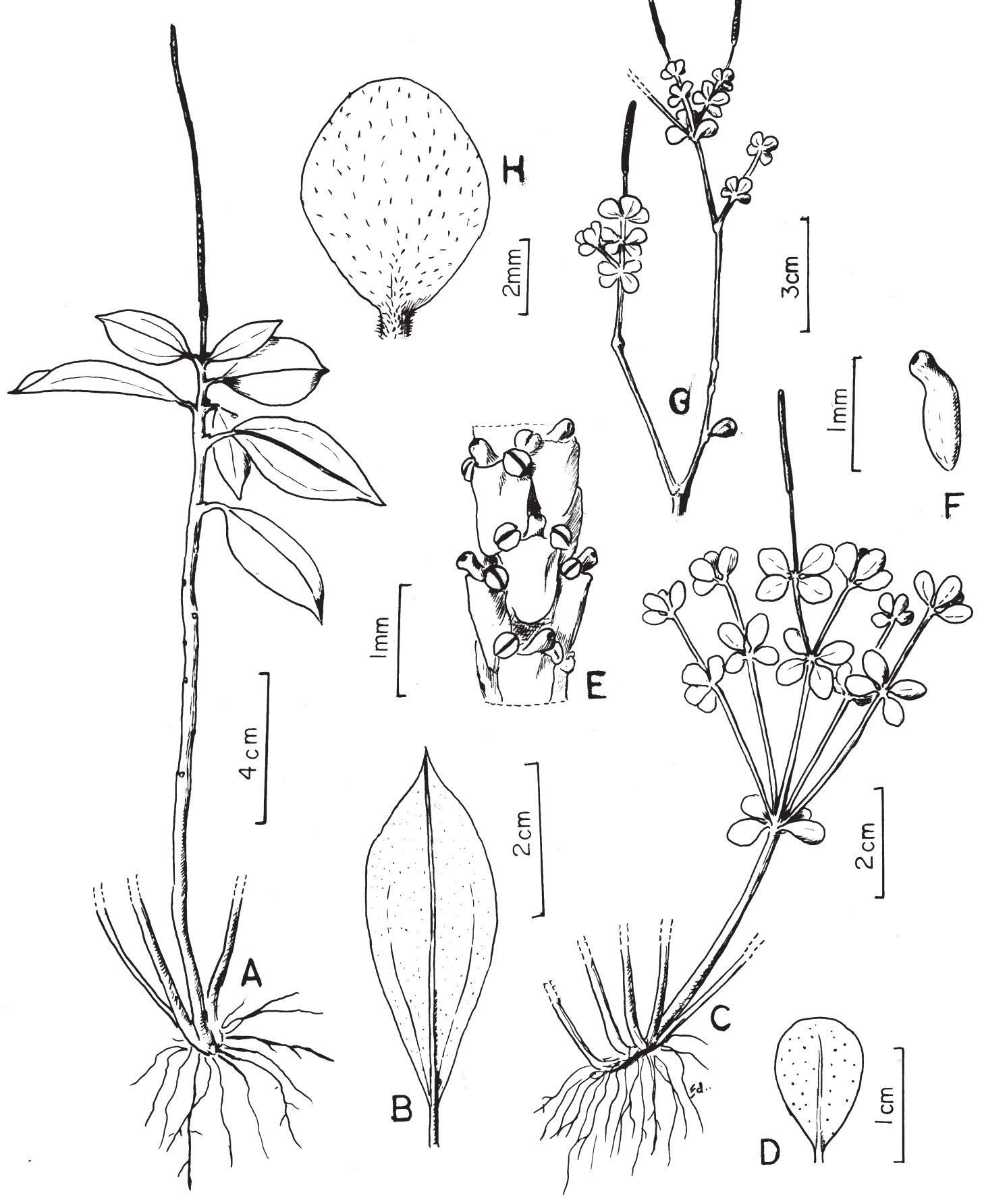

Fig. 1. PIPERACEAE. Peperomia subrubricaulis: A. Hábito. B. Folha, face abaxial. P. quadrifolia: C. Hábito. D. Folha, face abaxial. E. Detalhe da inflorescência. F. Gineceu. P. tetraphylla: G. Ramo florífero. H. Folha, face abaxial. (A-B: Zappi et al. CFCR 8480; D-F: Cavalcanti et al. CFCR 8479; G-H: Rossi et al. CFCR 1024). 